\title{
Do microorganisms obey macroecological rules?
}

\author{
Jonathan Dickey ${ }^{1}$, Rachel Swenie ${ }^{1}$, Sophia Turner ${ }^{1}$, Claire Winfrey ${ }^{1}$, Daniela Yaffar ${ }^{1}$, \\ Anchal Padukone ${ }^{1}$, Kendall Beals ${ }^{1}$, Kimberly Sheldon ${ }^{1}$, and Stephanie Kivlin ${ }^{1}$ \\ ${ }^{1}$ The University of Tennessee Knoxville
}

July 23, 2020

\begin{abstract}
Understanding the factors controlling the relative abundance, distribution, and diversity of organisms is a fundamental challenge in ecology. For plants and animals, macroecological rules have been developed that describe these large-scale distributional patterns and attempt to explain the underlying physiological and ecological processes behind them. Similarly, microorganisms exhibit patterns in relative abundance, distribution, and diversity across space and time, yet it remains unclear the extent to which microorganisms follow macroecological rules initially developed for macroorganisms. With rapid advancements in sequencing technology, we have seen a recent increase in microbial studies that utilize macroecological frameworks. Here we review and synthesize these macroecological microbial studies with two main objectives: (1) to determine to what extent macroecological rules explain the distribution of host-associated and free-living microorganisms, and (2) to understand which environmental factors and stochastic processes may explain these patterns among microbial clades (archaea, bacteria, fungi, protists) and habitats (host-associated and free living; terrestrial and aquatic). Our review is the first, to our knowledge, that examines whether or not the same environmental drivers contribute to similar trends to macroecological studies when rules are upheld for microorganisms. Further, we outline several outstanding questions and recommendations for future studies in microbial ecology.
\end{abstract}

\section{INTRODUCTION}

Understanding the factors that determine the abundance, distribution, and diversity of organisms across spatial and temporal scales is a fundamental challenge in ecology. For plants and animals, manymacroecological rules (also known as "ecogeographic rules") have been theorized to explain the physiological and ecological processes that underlie these patterns. Microorganisms also exhibit patterns in abundance, distribution, and diversity over space and time (Martiny et al. 2006, 2011; Hanson et al. 2012; Talbot et al. 2014; Kivlin 2020). Yet it is unclear whether macroecological rules developed for plants and animals apply to microorganisms and if they could be used to encourage best practices and improve predictions for abundance, distribution, and diversity of microorganisms. (Prosser et al. 2007; Soininen 2012; Shadeet al. 2018; Kivlin et al. 2020). Defining which macroecological rules are universal across the tree of life will allow for ecosystem-wide development of theory of common mechanisms affecting community assembly, response to global change, and recovery from human-induced disturbance.

Some macroecological rules should apply across the spectrum of life. For example, those that describe patterns of abundance or biodiversity of plants and animals (e.g., latitudinal/altitudinal clines in biodiversity, species-area relationships, species-abundance distributions, island biogeographic patterns) easily translate to microorganisms since these rules share a common theoretical underpinning of expanding the drivers of localbased community assembly to larger scales. Community assembly of all organisms, including microscopic ones, is driven by deterministic and stochastic processes (Vellend 2010; Nemergut et al. 2013). Deterministic processes include environmental selection or filtering, and biotic interactions such as competition and facilitation (Funk et al. 2008; Goldford et al. 2018). Stochastic processes that affect community assembly 
include dispersal limitation, neutral processes of ecological and evolutionary drift (Hubbell 2001; Martiny et al. 2011), priority effects of colonization (Fukami et al. 2010), legacy effects of previous environmental conditions (Hawkes et al.2017), and historical vicariance of geographic position of land masses (Matheny et al. 2009) or suitable habitat (Takacs-Vesbachet al. 2008). Because these explanatory drivers of community assembly apply regardless of the focal organism, community-level macroecological patterns driven by these processes should hold across the tree of life (Horner-Devine et al. 2004; Shade et al.2018).

In contrast, other organismal and functional macroecological rules, such as the Metabolic Theory of Ecology (Brown et al. 2004), Bergmann's Rule (Bergmann 1847), Foster's Rule (Foster 1964), and Rapoport's Rule (Stevens 1989) may lack direct analogs to microbial consortia because the mechanisms posited to underlie these rules relate to traits (e.g., body size, thermoregulation, or homeostasis) that may not exist in microorganisms or that are difficult to measure. This is particularly true of macroecological rules that assume sexual dimorphism of two sexes (Rensch's Rule; Rensch 1950), which apply well to many animals but break down in organisms with simpler (e.g., asexual bacteria) or much more complex mating systems (e.g., fungal species with hundreds of mating types). Moreover, macroecological rules based on body size lack direct analogs for most microorganisms where body size could be thought of as cell size, colony size or sporocarp size. Even if a consensus could be reached, DNA-based inference of microbial abundance is unlikely to represent cell size or abundance when ribosomal copy number varies 100 -fold among microbial taxa and lacks clear phylogenetic signal (Lofgren et al. 2019).

In addition to whether or not macroecological rules apply to microorganisms, microbial groups may also vary in their ability to conform to macroecological rules of plants and animals due to differences in habitat. For example, dispersal limitation of soil-borne and plant-associated microorganisms should be much higher compared to air-borne, water-borne, or animal-associated microorganisms that are actively transported as animals explore surrounding landscapes. This could limit range sizes of terrestrial and plant-associated microorganisms relative to aquatic or animal-associated microorganisms. In addition, climate fluctuations of terrestrial ecosystems may be more pronounced than those in aquatic ecosystems, which could affect organism range sizes (Sorte et al. 2013). Finally, biotic interactions may be more tightly linked in confined terrestrial spaces (e.g., soil pores) compared to large or more well mixed aquatic and marine ecosystems.

Perhaps one of the most crucial distinctions among microbial lifestyles is that of free-living versus hostassociated microorganisms (Figure 1 ). Some microorganisms are free-living in the environment in soil and water substrates. Distributions of these taxa may be mostly affected by dispersal limitation and subsequent environmental filtering, where contingencies such as dormancy (Lennon \& Jones 2011) or reduced metabolic rates (Wisnoski et al. 2020) allow some microorganisms to cope with unfavorable environmental conditions. However, a large portion of microbial diversity lives in symbiosis inside (endophytic ) or on (epiphytic ) animal and plant tissues. For many vertically transmitted host-associated microorganisms in animals and some plants, dispersal of the microorganism often depends on dispersal of the host (Salerno et al. 2016; Shade et al. 2017), eventually leading to co-cladogenesis in each group (Takiya et al. 2006; Schardlet al. 2008) and a strong signal of biotic filtering on the microbiome among hosts. This is especially true when host-associated microbes are more buffered from environmental conditions compared to free-living microorganisms. Multiple lines of evidence suggest that host-associated microorganisms (especially vertically transmitted microorganisms) often have narrower thermal tolerances (Dunbar et al. 2007; Kikuchi et al. 2016) and reduced genome sizes and functions (Moran et al. 2008). However, for other plant-associated microorganisms (e.g., mycorrhizal fungi), independent dispersal of plants and microorganisms allows dispersal limitation and environmental filtering (Hazard et al. 2013) to influence host-associated microbial communities.

In this review, we synthesize macroecological trends of free-living and host-associated microorganisms from terrestrial and aquatic ecosystems to understand the extent to which microorganisms follow the same largescale macroecological patterns as animals and plants. The objectives of this review are to (1) Determine to what extent macroecological rules explain the distribution of host-associated and free-living microorganisms, and (2) understand which environmental factors most affect the distributions of host-associated versus free- 
living microorganisms among microbial clades and habitats. We focus on six macroecological rules at the organismal level (Gloger's Rule, Rapoport's Rule, Abundance/Occupancy Relationships, Bergmann's Rule, Foster's Rule, Rensch's Rule), three rules that describe/explain community assembly and biodiversity (Theory of Island Biogeography, Species-Area Relationships, Latitudinal Diversity Gradient), and one functional rule (Metabolic Theory of Ecology).

For each rule we collected studies by querying Web of Science or Google Scholar with the search terms "rule name" AND "micro*" or "fung*" or "bacteri*" or "protist*" or "archaea" (query completed 06.15.2020). Because many studies report trends consistent with these rules without studying them directly, we also surveyed all papers that were cited by or cited the papers in our query. We did not include human-associated microorganisms in our survey. This search resulted in 175 studies with 218 records across all continents. For each study, we classified which macroecological rule(s) were surveyed and each study organism (archaea, bacteria, fungi, or protist), habitat (terrestrial or aquatic/marine), and niche (free-living or host-associated). We considered species-area relationships only for contiguous habitats and included species-area relationships among island-like habitats (e.g., lakes, tree holes, plant rhizosphere, animals) with other island biogeography studies. When the data were available, we classified which deterministic (e.g., resources and climate) and stochastic (e.g., dispersal limitation, priority effects) drivers were correlated with each observed macroecological pattern. Despite collecting 218 records for this synthesis, data limitation precluded a quantitative meta-analytical approach to addressing both adherence of microorganisms to macroecological rules and the environmental drivers influencing these distributions. Instead, we use vote counting (Hedges \& Olkin 1980) to define which macroecological rules were supported among microbial guilds and lifestyles and which environmental factors may have influenced these distributional patterns. While vote counting techniques are sensitive to sample size within studies, this analysis clearly demonstrates both when microbial distributions conform to macroecological rules and more importantly when gaps in scientific inquiry do not allow us to make this conclusion.

\section{ORGANISMAL MACROECOLOGICAL RULES}

\section{Gloger's rule}

Gloger (1833) observed a relationship between plumage coloration and climate variation in birds, predicting that darker coloration due to pigmentation occurred in warmer, more humid tropical regions while lighter colors occurred in cooler areas towards the poles. There is limited evidence for Gloger's rule in organisms other than animals. However, pigments such as melanin are also an important protective mechanism for many microorganisms, since darker pigments can provide protection from ionizing radiation and desiccation (Dadachova \& Casadevall 2008; Fernandez \& Koide 2013). Pigmentation may also play a role in thermoregulation and energy exchange by increasing or decreasing light absorption or reflectance (Cordero et al. 2018). Consequently, pigmentation could potentially provide an important adaptive function for microbes.

However, rather than following Gloger's rule, evidence from microbial distributions thus far supports the theory of thermal melanism, whereby greater melanism increases solar radiation absorption (e.g., Kettlewell 1973; Brakefield 1984). This has been shown both observationally and experimentally in yeast where pigmentation increases heat capture. For example, in contrast to Gloger's rule, free-living, dark-pigmented yeasts were found more often outside of the tropics (Cordero et al. 2018). This suggests pigmentation provides an adaptive advantage for these microorganisms at higher latitudes by increasing heat capture. Similarly, a survey of 3000 European macrofungal assemblages showed mushrooms were more darkly colored in colder climates (Krah et al. 2019). Mean temperature and in some cases, seasonality, were identified as drivers of mushroom coloration, and increased reproductive success was suggested as a potential advantage of darker pigmentation in colder climates. While suggestive that Gloger's rule may not apply to microorganisms, evidence thus far is mainly derived from free-living fungi and has not been examined in other microbial groups.

\section{Rapoport's rule}

Rapoport's rule states that the latitudinal ranges of plants and animals are greater at higher compared 
to lower latitudes (Stevens 1989). Stevens (1989) originally proposed a mechanism underlying this rule that relates to the climatic conditions under which different organisms have evolved. Specifically, species at higher latitudes must be able to handle greater temporal variability in climate compared to species at lower latitudes. As a result, species that have evolved at higher latitudes should be able to occupy larger latitudinal extents than species at lower latitudes. The rule was later extended to elevational gradients with the expectation that at higher elevations, climate is more variable and thus high elevation species should have broader elevational ranges (Stevens 1992). Other possible mechanisms for the rule have since been proposed, such as decreasing land area available to species at lower latitudes, reduced competition at higher latitudes, or extinction of species with narrow ranges at high latitudes due to glaciation (Gaston et al. 1998).

Studies examining Rapoport's rule in plants and animals suggest that the rule holds for certain taxa, in certain locations, and that multiple mechanisms are likely contributing to the observed pattern (Rohde 1996; Gaston \& Chown 1999). The pattern tends to be weaker in marine compared to terrestrial systems and in the Southern compared to Northern Hemisphere (Ruggiero \& Werenkraut 2007). The rule has received such mixed support that some researchers have questioned whether it is "time for an epitaph" for Rapoport's rule (Gaston et al. 1998). Despite this, ecologists are still intrigued by this ecogeographical rule and continue to examine whether it holds in a host of taxa, including microorganisms.

Thus far, support for Rapoport's rule across latitude and elevation in microorganisms is equivocal at best. In terrestrial systems, the latitudinal ranges of fungal taxa (Tedersoo et al. 2014; Coxet al. 2016) and ciliates appear to increase toward the poles (W. Foissner, pers. comm. to Azovsky and Mazei (2013)). By contrast, Learet al. (2017) observed smaller range sizes of bacterial taxa at higher latitudes in 204 streams along a $1000 \mathrm{~km}$ latitudinal gradient. In marine systems, a global study of bacteria found strong support for Rapoport's rule, with bacteria in the tropics having smaller ranges than bacteria in temperate regions (Amend et al. 2013). The relationship was so strong that the most abundant bacteria in the tropics were completely absent from higher latitudes, but even narrowly distributed bacteria in temperate regions were found at lower latitudes (Amend et al. 2013). A second study of marine bacteria also found that bacteria showed narrower ranges at lower compared to higher latitudes, but this was only true for bacteria in the phylaBacteroidetes and Cyanobacteria and the classes $\alpha-, \beta$-, and $\gamma$ - of the phylum Proteobacteria (Sul et al. 2013). In contrast, bacteria in the phyla Firmicutes, Chlamydiae ,Chloroflexi, Planctomycetes and those in the class Epsilonproteobacteria did not follow Rapoport's rule (Sul et al.2013). Researchers have found a reverse Rapoport's rule in marine benthic ciliates. One study found that ciliates had narrower ranges at higher latitudes (Azovsky \& Mazei 2013). Support is also mixed for an elevational Rapoport's rule. In a study across fungal phyla (Basidiomycota, Ascomycota, Zygomycota, Chytridomycota and Glomeromycota ), fungi at higher elevations had greater distributional ranges (Ogwu et al. 2019). In contrast, bacteria and diatoms in streams in Asia and Europe did not follow an elevational Rapoport's rule (Teittinen et al. 2016; Wang \& Soininen 2017).

Researchers have identified several possible mechanisms leading to the distributions of microorganisms across latitudinal and elevational gradients. Range sizes of some taxa have been associated with variation in temperature and precipitation (Lear et al. 2017), suggesting that environmental selection determines ranges. However, evidence from other studies suggests that dispersal limitation may be the primary driver of range sizes in microorganisms at larger spatial scales, with environmental selection, competition, and niche differentiation becoming important factors at smaller spatial scales (Mittelbach \& Schemske 2015). More manipulative experiments are needed to uncover the mechanisms driving range sizes of microorganisms to provide greater understanding of the importance of various processes at different spatial scales.

\section{Abundance/Occupancy Relationships}

The abundance-occupancy (A/O) relationship refers to the prevalent pattern among macroorganisms, whereby more abundant species occupy more locations within a given range (Gaston et al. 2000). It has been shown both within and among species. Most A/O relationships report positive correlations but fail to investigate the potential reasons why this relationship forms. There are a handful of studies that show weakly positive, or even negative trends amongst plants (Boeken \& Shachak 1998), fish (Marshall \& 
Frank 1994), and birds (Blackburn et al.1999b). In addition, evidence of positive A/O relationships have been found for microorganisms, with protists (Warren \& Gaston 1997), bacteria (Holt et al. 2004), and freshwater diatoms (Heino \& Soininen 2006; Spatharis et al. 2009; Soininen \& Teittinen 2019).

In general, the mechanisms resulting in the A/O pattern are not well understood. The A/O relationship can occur when extinction and colonization are density-dependent (Warren \& Gaston 1997). In experimental microcosms with constant resources, when dispersal was allowed, the relationship tracked the carrying capacity hypothesis (i.e. locally abundant species have lower extinction and higher colonization rates than species with low abundance; Holt et al. 2002). However, this study found that the relationship was not contingent on dispersal; without dispersal, the A/O relationship arose through extinction (Holt et al. 2002). Moreover, the A/O relationship does not always depend on environmental resource consistency. For example, the relationship held in heterogeneous environments, though to a lesser degree than in homogeneous environments (Holt et al.2004). In field-based observations, the A/O relationship has been observed with soil fungal assemblages where dispersal was shown to have less of a role (Kivlin et al. 2014). Mechanisms behind this pattern were attributed to soil nutrients, though the relationship was weak (Kivlin et al. 2014).

Niche-based processes can also create A/O relationships among organisms. In microcosm experiments with protists, biotic interactions strengthened A/O relationships (Holt et al. 2002). Likewise, in natural systems Rocha et al. (2018) found that niche-based variables were the primary predictors for the positive A/O relationship they observed in freshwater diatoms and that the effect of niche breadth on the relationship was less important than local environmental niche position. In animal host-associated intestinal bacteria, Green et al.(2016) found support for the A/O relationship that they attributed to multiple factors, including dispersal limitation, host selection, historical contingency, and stochastic processes.

\section{Bergmann's rule}

Bergmann's rule, which states that body size decreases among congeneric species with decreasing latitude, has primarily been studied in mammals and birds. Not all birds and mammals follow the rule, and even fewer smaller organisms, such as insects, conform to it (Blackburn et al. 1999a; Meiri \& Dayan 2003). However, some evidence supports Bergmann's rule in microorganisms, such as bacterioplankton (Meador et al. 2009), with smaller cells at higher temperatures (Daufresne et al. 2009).

We found no studies testing a mechanism behind this pattern in microorganisms, but one explanation for Bergmann's rule among prokaryotes may be that as temperature increases, nucleic acid content decreases, resulting in smaller cells (Huete-Stauffer et al.2016). Though studying this rule in microorganisms may provide useful insights for the evaluation of the ecological impacts of global change on microbiota, there are significant challenges in defining the size of many microorganisms, such as multicellular fungal hyphae, that must be standardized before rigorous comparisons can be drawn.

\section{Organismal rules with no evidence (Rensch's rule, Foster's rule)}

Rensch's rule describes a pattern of increasing sexual size dimorphism with increasing body size in species where males are larger than females and decreasing sexual size dimorphism where females are larger than males (Rensch 1950). The rule appears widespread in animals and particularly birds, where strength of sexual selection is the strongest predictor of Rensch's rule (Dale et al. 2007). This rule has not been tested in microorganisms, to our knowledge, because most microorganisms lack distinct sexes. Prokaryotic microbes such as bacteria are predominantly asexual, while eukaryotic microbes such as fungi and protists may reproduce clonally or through diverse recombination strategies (Narra \& Ochman 2006; Ni et al. 2011; Weedall \& Hall 2015). Furthermore, body size can be difficult to assess among microorganims due to their small size and body plans that may change across the lifecycle (i.e. filamentous fungi, which possess differing vegetative and reproductive forms).

Another macroecological rule that examines body size patterns is Foster's rule, where taxa show increased or decreased body size on islands compared to mainland populations (Foster 1964; Van Valen 1973). Foster's rule has been studied extensively among mammals and a variety of other animals, but support for the rule 
is mixed even for mammals and particularly low for non-mammalian species (Lokatis \& Jeschke 2018). No study, to our knowledge, has examined Foster's rule for microorganisms.

\section{COMMUNITY LEVEL MACROECOLOGICAL RULES}

\section{Theory of Island Biogeography}

The dynamic equilibrium theory of island biogeography is an influential framework for understanding species diversity patterns. Its original proponents (MacArthur \& Wilson 1967) predicted two general patterns: (1) larger islands have more species at equilibrium, since extinction rates decline and colonization rates increase with increased area and (2) islands at a greater distance from the "mainland" or source population have fewer species at equilibrium, as colonization rates decrease with distance. Traditionally applied to groups of oceanic islands, the theory has recently been used to understand microbial biogeography across patchy, island-like systems. These include roots (Peay et al. 2007), leaves (Andrews et al. 1987; Kinkelet al. 1987), lakes or pools (Reche et al. 2005), and non-human animal organs (Loudon et al. 2016; Moeller et al. 2017). The theory has also been applied to other discrete habitats that are separated by sharp differences in temperature (Whitakeret al. 2003; Darcy et al. 2018), substrate textural or chemical qualities such as oxygen availability or host-secreted metabolites (Loudon et al. 2016), or other abiotic factors that have been shown to structure microbial distributions.

Results from several studies support the general relationship between microbial diversity and island size, although there is no consensus on how habitat size is measured amongst varying "island-like" systems (Itescu 2019). For example, Darcy and colleagues (2018) observed that bacterial diversity within cryoconite holes in Antarctic glaciers is positively correlated with hole area, whereas Bell et al. (2005) found bacterial genetic diversity in water-filled tree holes increased with water volume. Studies have also found fungal species richness increases with tree host population size in arctic and alpine environments (Chlebicki \& Olejniczak 2007) and as a function of tree photosynthetic tissue volume in ectomycorrhizal fungi (Peay et al. 2007; Glassman et al. 2017a). Yet, some studies fail to detect a significant relationship between species diversity and island area, such as AM fungal communities on true islands, bacterial richness in oak litter patches and filamentous fungi on apple leaves (Kinkelet al. 1987; Davison et al. 2018; Spiesman et al.2018). In some cases, the lack of an observed relationship is likely because environmental heterogeneity relevant for the focal taxa does not scale with island size (Teittinen \& Soininen 2015).

The mechanisms that produce island area and microbial diversity patterns are still debated. Recent studies have found these patterns hold even after explicitly accounting for environmental variables. For example, forest fragment size predicted diversity of root-associated fungi in a dominant tree even after accounting for the effects of soil carbon (Vannette et al. 2016). Dinnage et al. (2019) determined that tree size explained more variation in rhizobia diversity than other edaphic factors. Various host-associated microbial clades have differing responses to ecological drift, host size, and other environmental factors (Chlebicki \& Olejniczak 2007; Dinnage et al. 2019; Liet al. 2020). Bacterial alpha diversity increased with island area, which may be explained by differences in overall immigration and extinction rates. However, fungal beta diversity increased with area, which instead suggests an effect of greater microenvironmental variation in larger patch sizes. Further research into mechanisms underlying diversity-area patterns may clarify such differences across taxa, although studying processes such as local extinction in microbial communities may not be straightforward, particularly in natural systems (but see Andrews et al. 1987).

Empirical evidence that microbial diversity and community similarity decline as a function of distance from the source population is mixed across the literature, reflecting taxon-specific patterns as well as the need for more research. A significant challenge in applying island biogeographic theory to microbial communities in island-like systems is that the microorganism source, or "mainland" population, is often difficult to define, and thus most studies instead consider only distances among islands. Interestingly, most of the studies that assess the effects of distance from the mainland have used the roots of isolated or planted pine trees as "islands" and a denser, nearby pine forest as the "mainland" (Peay et al. 2010, 2012; Bahramet al. 2013; Glassman et al. 2017a, b). For example, Bahram et al . (2013) and Glassman et al . (2017a) both found that 
ectomycorrhizal community similarity and diversity declined with increased distance from the natural forest's edge. The majority of studies examining how distance among "islands" shapes community similarity and diversity find spatial autocorrelation. For instance, communities of hot spring-dwelling archaea (Whitaker et al. 2003) and protists in lakes (Lepère et al. 2013) become more dissimilar as a function of distance, rather than variation in environmental factors. This suggests that for these organisms, the difficulties of dispersing among patches of suitable habitat is more important for community structure than environmental filtering.

Exceptions to the predictions of island biogeographic theory reveal that the relative importance of environmental filtering and dispersal limitation is taxon- and scale-specific. For example, Vannette et al . (2016) determined that the degree of forest fragment isolation was important in structuring the communities of some classes of root-associated fungi but not others. In other cases, lack of support may instead be due to the spatial scale considered. Darcy et al . (2018) observed positive spatial autocorrelation of cryoconite glacier hole bacterial communities among glaciers, but very little within glaciers, suggesting that had they sampled at a smaller scale, they may not have found evidence in line with island biogeographic theory. The importance of scale is also taxon-specific because taxa differ in their dispersing and colonizing abilities (Peay et al. 2012), likely explaining why Teittinen \& Soininen (2015) did not find spatial structuring of diatom communities in springs. Overall, more manipulative experiments to assess why and how taxa differ in their dispersal capacities would help assess the relevance of an island-distance relationship for microorganisms.

\section{Species-Area Relationships}

The positive relationship between species richness (S) and the surveyed area (A) is one of the clearest, least disputed macroecological patterns and is fundamental to understanding the inherent heterogeneity of global biodiversity (Arrhenius 1921). The power-law $\mathrm{S}=\mathrm{cA}^{z}$ has been used to compare the relationship between species number and area, where $c$ is the intercept and the exponent $z$ measures the rate of community turnover across a standardized spatial scale. This phenomenon has been explored across a myriad of taxa, including birds (Jetz \& Rahbek 2001), mammals (Lomolino 1982), plants (Honnay et al. 1999), terrestrial microbial eukaryotes (Green et al. 2004), soil bacteria (Horner-Devineet al. 2004), aquatic bacteria (Reche et al. 2005; Martinyet al. 2011), ectomycorrhizal fungi (Peay et al. 2007), and vertebrate gut bacteria (Godon et al. 2016). Yet, the power-law often fails to predict species richness for many organisms (McCoy \& Connor 1976; Connor \& McCoy 1979) indicating that this relationship may only apply to a subset of spatial scales (i.e. local or regional), habitat types, or taxonomic groups.

Among microbial studies that investigate species-area or taxa-area relationships, microbial diversity often increases with spatial scale but to a much lower extent (slope $z=0.02-0.1$ ) than observed for macroorganisms (slope $z=0.3-0.6$, see Green \& Bohannan (2006) and references therein). Moreover, the shape of this relationship is often monotonic and does not follow the proposed power-law for larger organisms. Spatial scaling of microbial diversity may vary from that of macroorganisms for many reasons including the higher diversity of microorganisms versus macroorganisms, loose species definitions for microorganisms, dormancy of microbial taxa (Jones \& Lennon 2010), or extracellular DNA confounding species richness estimates (Cariniet al. 2016).

In addition to methodological concerns, many variables other than spatial extent affect the distribution of free-living and host-associated microorganisms. For example, microbes associated with marshland habitat respond to both geographic distance and sediment moisture (Horner-Devine et al . 2004). While species-area relationships are beginning to be explored across microbial systems, many confounding factors exist among comparative studies, such as differences in spatial extent or environmental heterogeneity. Illustrating this point is the finding that the rate of community turnover depends on whether microbial species richness is measured within or across habitats (Martiny et al . 2011). In addition, determining patterns of species richness over space is even more intractable for host-associated microbial taxa, such as ectomycorrhizal fungi, where host effects and dispersal limitation might conflate the relative importance of various factors in prediction of species richness (Tanesaka 2012). Nevertheless, despite the shape of the relationship of species richness and area, taxa within most microbial guilds and lifestyles increase in diversity across space. 


\section{Latitudinal Diversity Gradient}

The Latitudinal Diversity Gradient (LDG), whereby biodiversity increases from the poles to the equator, is a common large-scale pattern in ecology (Jablonski et al. 2006). Many invertebrate and vertebrate species manifest this gradient, as do vascular plants and some fungi and marine bacteria (Hillebrand 2004). However, many macro- and microorganisms do not exhibit a latitudinal diversity gradient (Fuhrman et al. 2008; Gillman et al. 2015), owing to legacies of environmental disturbance, dependence on environmental factors that do not trend with latitude, or dependence on biotic interactions with other organisms whose diversity also does not scale linearly with latitude.

Early reports on microbial diversity suggested that some fungi and marine bacteria may follow the classic LDG pattern much as plants and animals do (Hillebrand 2004). Further studies confirmed this pattern in stream diatoms, marine bacterioplankton, marine tintinnids, Streptomyces bacteria, freshwater fungi, and most fungal taxonomic groups (Fuhrman et al. 2008; Tedersoo et al. 2014; Hyde et al. 2016; Andamet al. 2016). The main drivers of this pattern were mean annual precipitation, temperature, carbon availability, and substrate $\mathrm{pH}$. However, a number of studies show that microbes tend to follow a hump-shaped diversity pattern within a hemisphere such that the greatest diversity is found in temperate areas. This trend was demonstrated in planktonic bacteria (Milici et al. 2016), ectomycorrhizal fungi (Tedersoo et al . 2014), aquatic hyphomycete fungi (Jabiolet al. 2013; Duarte et al. 2016), and saprotrophic stream fungi (Seena et al. 2019). Potential drivers of this type of distribution include sea water temperature, thermoclines, day length, and phosphorus levels for aquatic species, dispersal limitation in terrestrial microbes, and plant host-related diversity and distribution in ectomycorrhizal fungi.

Other patterns of diversity have also been found across latitude. A study of stream diatoms found that richness showed a U-shaped pattern. However, the study ranged only from subtropical to temperate latitudes in the northern hemisphere (Passy 2010). Thus, a different pattern might have been observed had a larger latitudinal gradient been examined. In addition, for both the hump-shaped and U-shaped diversity distributions, sampling bias toward temperate areas may have influenced these results. Overall, a majority of studies found no pattern in microbial diversity across latitude. These include microbes in the Pacific ocean (Baldwin et al.2005), marine free-living ciliates (Azovsky \& Mazei 2013), freshwater diatoms (Soininen \& Teittinen 2019), heterotrophic bacterioplankton (Schiaffino et al. 2013), autotrophic eukaryotes (Schiaffinoet al. 2016), soil bacteria (Fierer \& Jackson 2006; Hendershotet al. 2017), and soil fungi (Hendershot et al. 2017). Instead, soil $\mathrm{pH}$ was an important driver of distributions for terrestrial microorganisms in these studies, but localized climatic factors, nutrient availability, dispersal limitations, and scale of study may also play a role. Species richness of some ecto- and endoparasites also does not vary with latitude, since they are insulated from environmental conditions by their hosts (Rohde 1978, 1999).

\section{FUNCTIONAL MACROECOLOGICAL RULES}

\section{Metabolic Theory of Ecology}

The Metabolic Theory of Ecology (MTE) predicts that the metabolism of individual organisms increases with environmental temperature, often with a $3 / 4^{\text {th }}$ scaling to body size (Brown et al. 2004). Corollary predictions suggest that metabolic rates of all organisms are a combination of the allometric scaling of their body mass and biochemical kinetics (West et al. 1997) which leads to a negative association between population carrying capacity and temperature (Brownet al . 2004). While supported in some plant and animal systems, considerable controversy surrounds the universality of metabolic theory. For example, many underlying assumptions of metabolic theory, such as the actual scaling of surface area to volume ratio across organisms and enzymatic activation energies, remain untested or unproven across the tree of life (Duncan et al. 2007; Price et al. 2012).

In microbial systems, this theory has been extended to extracellular enzyme activities (Elias et al. 2014), which are assumed to reflect intracellular metabolic rates. Many studies across environmental temperature gradients find positive relationships between temperature and soil enzyme activities and respiration (Xu et al. 2017) as well as between temperature and microbial diversity (Okie et al.2015; Zhou et al. 2016; 
Wu et al. 2018). Similarly, meta-analyses confirm that metabolic efficiency (i.e. the quantity of resources incorporated into biomass relative to uptake) scales with body size among microorganisms in terrestrial and aquatic ecosystems (Sinsabaugh et al. 2015). However, metabolic scaling in microorganisms rarely follows the $3 / 4^{\text {th }}$ power to body size (DeLong et al. 2010) and studies are often confounded by other abiotic and biotic factors that also shift with temperature, such as variation in water, nutrient availability, plant diversity, or productivity (Zhou et al . 2016). Furthermore, thermal acclimation (Bradford et al. 2008) and adaptation (Alster et al. 2020) can alter microbial temperature responses in less than a decade. Thus, while evidence in support of metabolic scaling of microbial processes seems confirmatory, the rule should be examined more carefully across gradients that decouple temperature from other environmental drivers over evolutionary time. In addition, cell size is not linearly related to metabolic rates in marine phytoplankton communities (Marañón 2015), suggesting that the relationship between organismal size and metabolism may apply to aggregates of microorganisms but break down at the smallest, cellular scales.

\section{SYNTHESIS OF RESULTS}

Across all macroecological rules the majority of macroecological microbial studies (78\%) have been conducted on free-living microorganisms, mainly in aquatic ecosystems (Figure 2 ). In contrast, few studies have examined similar patterns in host-associated microorganisms with the notable exceptions of studies of latitudinal diversity and island biogeographic patterns focused on plant-associated fungi (e.g., mycorrhizal fungi and endophytes; Figure 2 ). Furthermore, the bulk of these studies examined community-level trends in microbial macroecology, with less than $35 \%$ of studies occurring at the organismal level (Figure 2 ). For community-based macroecological rules, latitudinal diversity gradients were more commonly studied, but patterns of microbial diversity did not consistently decrease from the equator to the poles, with reverse, hump-shaped, and indistinct diversity patterns prevalent across latitudes (Figure 3 ). In contrast, rules predicted by the dynamic equilibrium theory of island biogeography, which was the second most-studied community-based macroecological rule, were largely upheld in many systems (e.g. terrestrial host-associated mycorrhizal fungi, aquatic bacteria and protists) with increasing diversity on larger islands (but see notable exceptions, e.g., leaf endophytic fungi;Figure 3 ). Similarly, diversity was often negatively correlated with island distance from the source population, especially for plant-host associated microorganisms. For organism-based macroecological rules, microorganisms often followed the same patterns as macroorganisms (e.g., Bergmann's Rule, Rapoport's Rule), though evidence was sparse. Notably, Gloger's Rule of increasing pigmentation at lower latitudes was reversed for fungi in the only two published studies, which suggested that melanization was associated with thermal adaptation to colder, more polar latitudes. Finally, for functional-based macroecological rules, evidence for metabolic scaling of microbial function confirmed expected positive temperature-dependence but was examined in only 14 studies and never in host-associated microbial communities.

When macroecological rules were upheld in microorganisms, drivers of these patterns were mostly similar to those hypothesized for the macroorganisms studied to date (Table 1 ). For example, patterns consistent with the rules predicted by the dynamic equilibrium theory of island biogeography were often correlated with island patch size and dispersal, whereas latitudinal diversity gradients and metabolic scaling followed temperature gradients. Surprisingly, substrate $\mathrm{pH}$ was only related to species-area relationships and island size in island biogeography, despite its pivotal role in determining patterns of microbial beta-diversity at large spatial scales (Fierer \& Jackson 2006). Instead, other environmental factors related to climate and resources (carbon, nutrients) often were correlated with many microbial macroecological patterns. In addition, dispersal limitation and patch size were among the main correlates of microbial distributions, regardless of habitat or host-associated versus free-living status. While data were scarce, the distributions of host-associated microorganisms tended to be structured more heavily by biotic factors (e.g., host identity, microbial interactions) than were free-living taxa. Similarly, when comparisons were possible (e.g., Latitudinal Diversity Gradient, Species Area Relationship, Theory of Island Biogeography) there were no clear differences in drivers of terrestrial and aquatic microorganisms or among microbial kingdoms (Table 1 ). Clearly more investigation into several macroecological rules such as Gloger's Rule, Foster's Rule and Bergmann's Rule is warranted, as is more in-depth inquiry of the processes driving macroecological patterns, since over 30 studies found support 
for microbial congruence with macroecological rules but did not test or describe an underlying process to create these patterns.

Many factors should be considered when one compares these microorganismal trends to those of macroorganisms. Many microbial studies did not explicitly test a macroecological rule and were not searchable in Web of Science or Google Scholar. In addition, null results are less likely to be published. These factors could have biased our findings towards rule confirmation rather than exception. Biologically, patterns of microbial distributions obtained from sequencing may sample a different subset of organisms than those derived from observational studies of plants and animals. DNA-based sampling encompasses both dormant and active states, which may increase estimates of microbial diversity as compared to plants and animals. An analog would be to sample all plant and animal gametes, which clearly is not feasible. Microorganisms that undergo horizontal gene transfer or have higher DNA substitution rates may also evolve faster than macroorganisms, allowing greater ability to respond to microclimates and shifts in environments than plants and animals. This could be why microbial distributions seem to track local nutrients or niches more than would be predicted by theories mentioned above for macroorganisms.

\section{Outstanding Questions}

Several outstanding questions and subsequent discussion points remain after our synthesis. First, are there important environmental factors or interactions among environmental drivers specific to microbial taxa (e.g., soil pore size) that were not captured in previous studies? If so, can these explain some of the cases where microorganisms follow macroecological patterns but where the proposed causal mechanism for macroorganisms seems inapplicable? Second, how should we conceptualize traits of microorganisms, such as body size, to compare with macroorganisms? So far, microbial body size has been measured as cell size, but extensions to sporocarp or colony size could better reflect ideas of resource allocation and use underlying some theories of macroecology. Third, how do the evolutionary rates of microbial speciation and extinction affect our interpretation of macroecological rules, such as those associated with the Metabolic Theory of Ecology or the dynamic equilibrium theory of island biogeography? For example, are biologically diverse islands hotspots for speciation or cold spots for extinction, or are patterns relating to island biogeography theory solely driven by ecological dispersal trajectories? Finally, how does temporal turnover of microbial communities influence our conceptualization of macroecological patterns that are inferred from single time point studies? Are macroecological patterns of microorganisms consistent intra- and inter-annually? Data from multi-year studies may address most of these questions and can allow assessment of ecological and evolutionary turnover in microbial communities in a variety of habitats.

\section{Best Practices in Microbial Macroecology}

To spur future studies, we have developed a list of best practices for the future of microbial macroecology. First, we recommend hypothesis-driven inquiry where researchers use macroecological rules as null hypotheses instead of surveying DNA for de novo patterns.

Second, macroecological rules should be used as a framework to connect multiple factors influencing biogeographic patterns (e.g., patch size and dispersal limitation among islands).

Third, we should consider unique limitations and prospects of microbial ecology (microbial morphology and physiology, DNA-based studies, destructive sampling, horizontal gene transfer, pooling across replicates within sites for DNA sequencing) and interpret findings in this light (reviewed in Shade et al. 2018). When comparing macroecological rules across the tree of life, collection methods and statistics should be standardized as much as possible to avoid over-estimating microbial diversity, and efforts should be made to avoid temperate zone sampling bias by increasing tropical sampling. Fourth, researchers should examine more than DNA (e.g., organismal traits, metabolomes) when surveying microorganisms to understand organismal trait-based and functional macroecological patterns. Finally, we should conduct longitudinal studies across years to understand microbial fluctuations due to ecological and evolutionary processes. The future is open for many lines of inquiry into the patterns and processes underlying microbial macroecology. The promising analogs to established macroecological rules for macroorganisms and notable exceptions we found 
here provide a roadmap to guide forecasts of microbial distributions under current future environmental conditions.

\section{ACKNOWLEDGMENTS}

We thank members of the UTK Ecology and Evolutionary Biology and Microbiology departments for participating in the microbial macroecology seminars that inspired this synthesis. We also appreciate comments from Daniel Simberloff, Jennifer Schweitzer, and Colin Averill that substantially improved this work. KSS acknowledges funding from NSF IOS 1930829 and The University of Tennessee, Knoxville. SNK was funded by NSF DEB 1936195, Texas Ecological Laboratory and The University of Tennessee, Knoxville.

\section{FIGURES}

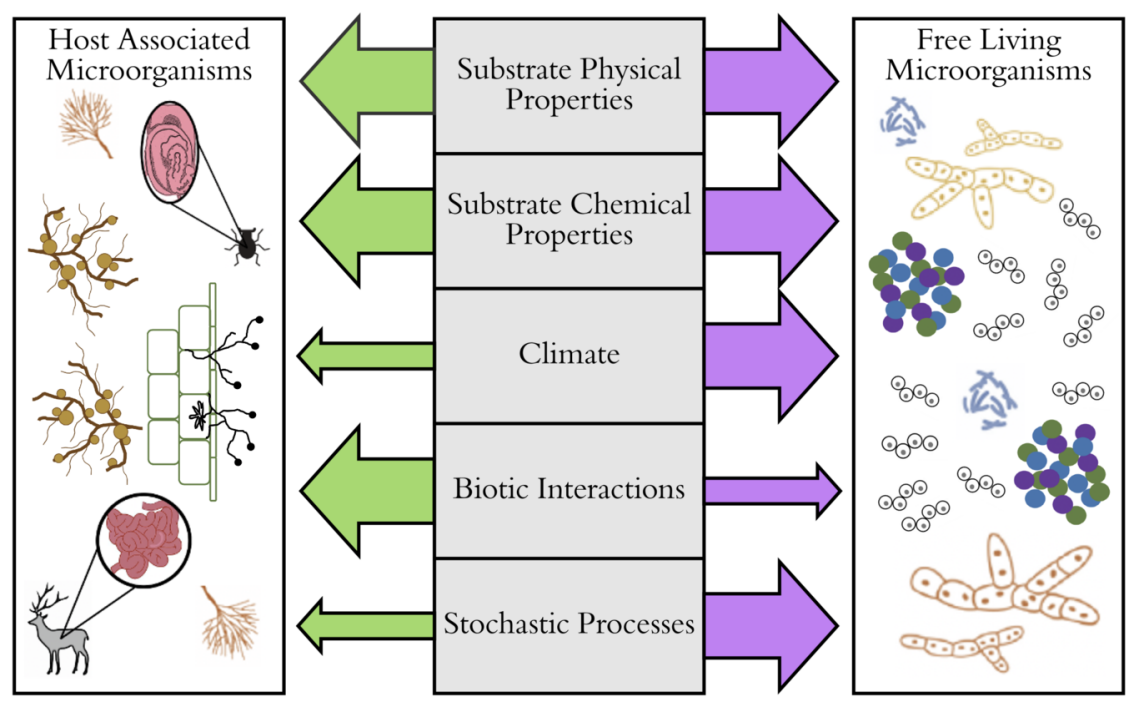

Figure 1. The predicted relative importance of ecological and evolutionary factors that drive the distributions of host-associated and free-living microorganisms. Here, the hypothesized strength of the factor is illustrated by the size of the arrow, with larger arrows representing stronger effects. Examples of host-associated microorganisms include bacterial microbiomes of beetle and deer digestive tracts, arbuscular mycorrhizal fungi, the absorptive hyphae of ectomycorrhizal fungi, and root nodule-forming bacteria (Rhizobium spp. ). Examples of free-living microorganisms include soil and aquatic aggregates of bacteria, fungi, and archaea and protists such as diatoms. 


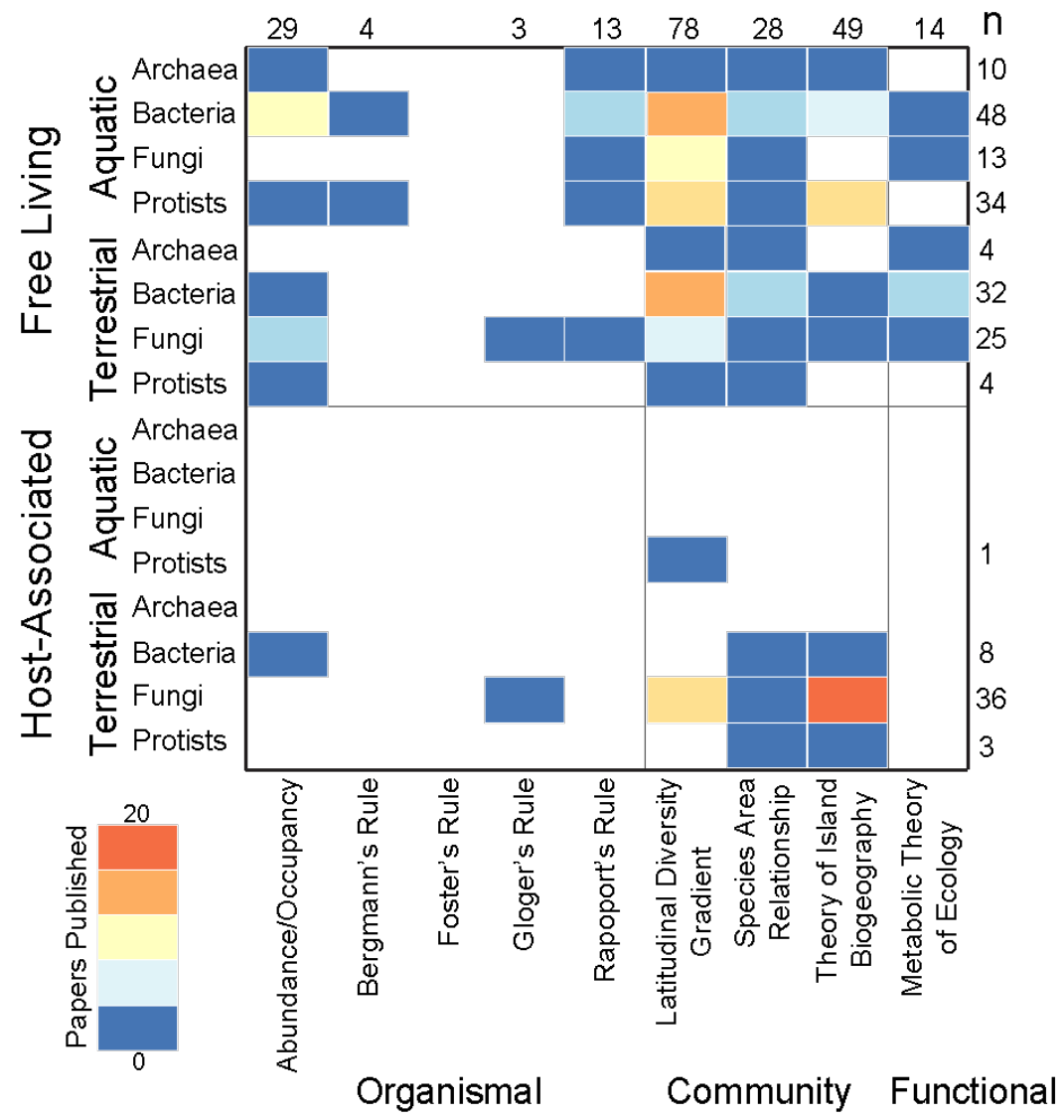

Figure 2. Numbers of publications for each queried macroecological rule across free-living and hostassociated microorganisms in aquatic and terrestrial environments. Heat map indicates number of publications per grid square with total number of publications denoted for each row and column on the left and top sides of the chart. 


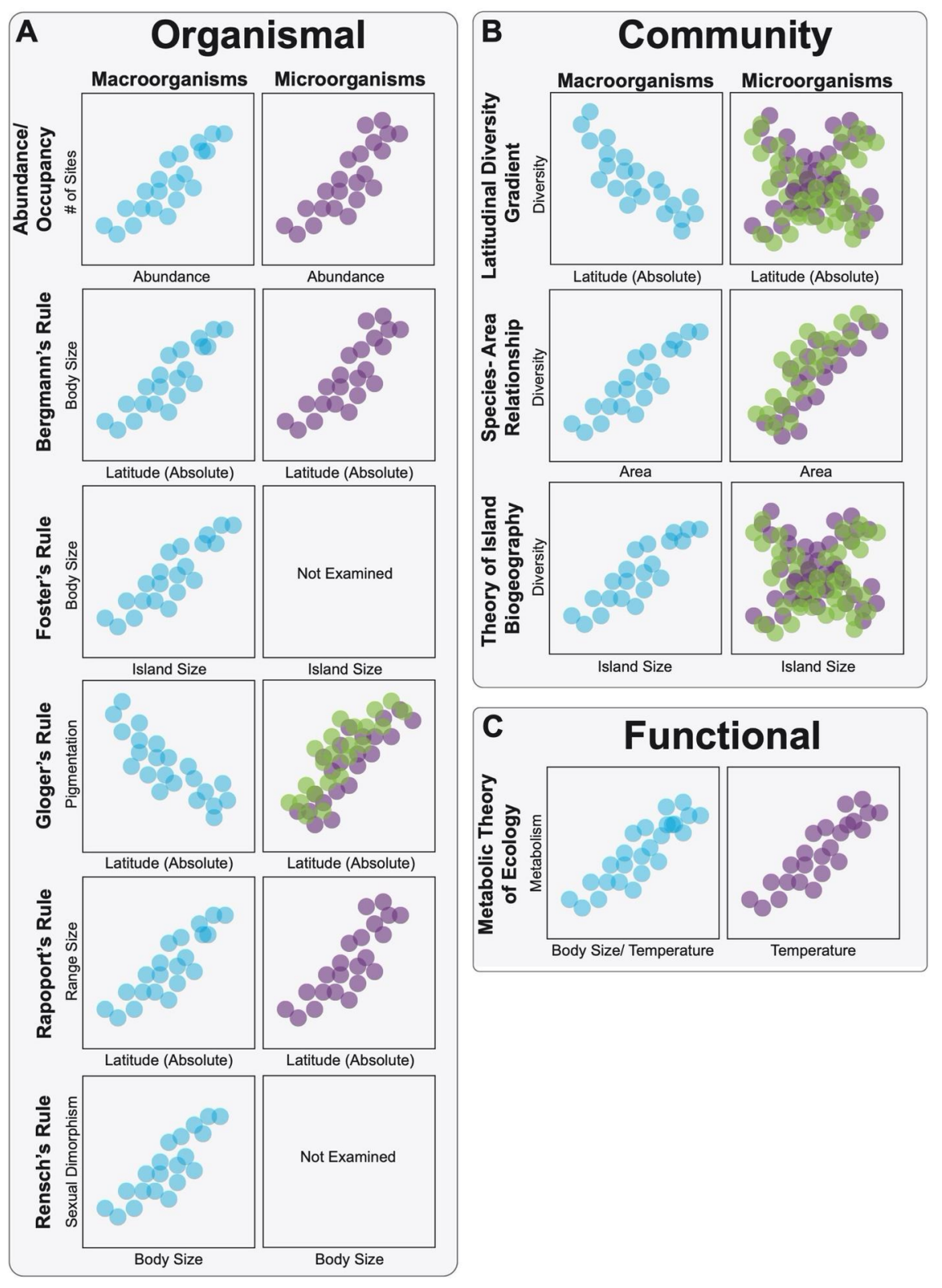

Figure 3. Predicted macroecological patterns based on proposed macroecological rules for plants and animals (blue) versus observed patterns for free-living (purple) and host-associated (green) microorganisms grouped at organismal, community, and functional levels. Microbial patterns match those of plants and animals for organismal (but see Gloger's Rule) and functional levels, but community-level patterns are variable, reflecting different ecological drivers of macro- and microorganism distributions.

TABLE 1. Evidence for drivers of each macroecological rule for microorganisms.

Text Box 1: Definitions

Endophyte: microorganisms that colonize inter- or intracellular space of plants, animals, and fungi.

Epiphyte: microorganisms that live on the surface of plants, animals, and fungi. 
Historical vicariance : Contemporaneously observed geographic disjunction in species ranges caused by historical severance of a contiguous species range due to separation of land masses or geological events (e.g., river gorges).

Island : An island is both a true island of land surrounded by water and island-like habitats that are spatially and temporally isolated from habitats of the same type (sensu Itescu 2019).

Legacy effects : Effects of prior environmental conditions on subsequent organismal physiology, diversity, composition, and distributions after environmental conditions have changed.

Macroecological rules : Generalizable patterns of organismal distributions, abundances, and diversity patterns supported by known processes of organismal physiology/community assembly and/or dispersal.

Microorganisms : Here we define microorganisms as microscopic fungi, bacteria, archaea, and protists.

Priority effects: When the order of arrival at a given habitat gives primary colonizers an advantage in using resources to be able to outcompete subsequent colonizers.

\section{REFERENCE LIST}

Alster, C.J., von Fischer, J.C., Allison, S.D. \& Treseder, K.K. (2020). Embracing a new paradigm for temperature sensitivity of soil microbes. Glob. Chang. Biol. , 26, 3221-3229.

Amend, A.S., Oliver, T.A., Amaral-Zettler, L.A., Boetius, A., Fuhrman, J.A., Horner-Devine, M.C., et al. (2013). Macroecological patterns of marine bacteria on a global scale. J. Biogeogr. , 40, 800-811.

Andam, C.P., Doroghazi, J.R., Campbell, A.N., Kelly, P.J., Choudoir, M.J. \& Buckley, D.H. (2016). A Latitudinal Diversity Gradient in Terrestrial Bacteria of the Genus Strepromyces. Am. Soc. Microbiol., 7, $1-9$.

Andrews, J.H., Kinkel, L.L., Berbee, F.M. \& Nordheim, E. V. (1987). Fungi, leaves, and the theory of island biogeography. Microb. Ecol. , 14, 277-290.

Arrhenius, O. (1921). Species and Area. Br. Ecol. Soc. , 9, 95-99.

Azovsky, A. \& Mazei, Y. (2013). Do microbes have macroecology? Large-scale patterns in the diversity and distribution of marine benthic ciliates. Glob. Ecol. Biogeogr. , 22, 163-172.

Bahram, M., Kõljalg, U., Kohout, P., Mirshahvaladi, S. \& Tedersoo, L. (2013). Ectomycorrhizal fungi of exotic pine plantations in relation to native host trees in Iran: Evidence of host range expansion by local symbionts to distantly related host taxa. Mycorrhiza , 23, 11-19.

Baldwin, A.J., Moss, J.A., Pakulski, J.D., Catala, P., Joux, F. \& Jeffrey, W.H. (2005). Microbial diversity in a Pacific Ocean transect from the Arctic to Antarctic circles. Aquat. Microb. Ecol. , 41, 91-102.

Bell, T., Ager, D., Song, J.I., Newman, J.A., Thompson, I.P., Lilley, A.K., et al. (2005). Ecology: Larger islands house more bacterial taxa. Science (80-. ). , 308, 1884.

Bergmann, C. (1847). Über die Verhältnisse der Wärmeökonomie der Tiere zu ihrer Grösse. Vol. 3. Göttinger Studien.

Blackburn, T.I.M.M., Gaston, K.J. \& Loder, N. (1999a). Geographic gradients in body size-a clarification of Bergmann's rule. Divers. Distrib. , 5, 165-174.

Blackburn, T.M., Gaston, K.J., Quinn, R.M. \& Gregory, R.D. (1999b). Do local abundances of British birds change with proximity to range edge? J. Biogeogr. , 26, 493-505.

Boeken, B. \& Shachak, M. (1998). The dynamics of abundance and incidence of annual plant species during colonization in a desert.Ecography (Cop.). , 21, 63-73. 
Bradford, M.A., Davies, C.A., Frey, S.D., Maddox, T.R., Melillo, J.M., Mohan, J.E., et al. (2008). Thermal adaptation of soil microbial respiration to elevated temperature. Ecol. Lett. , 11, 1316-1327.

Brakefield, P.M. (1984). Ecological studies on the polymorphic ladybird Adalia bipunctata in the Netherlands. II. Population dynamics, differential timing of reproduction and thermal melanism. J. Anim. Ecol. , 775-790.

Brown, J.H., Gillooly, J.F., Allen, A.P., Savage, V.M. \& West, G.B. (2004). Toward a metabolic theory of ecology. Ecology , 85, 1771-1789.

Carini, P., Marsden, P.J., Leff, J.W., Morgan, E.E., Strickland, M.S. \& Fierer, N. (2016). Relic DNA is abundant in soil and obscures estimates of soil microbial diversity. Nat. Microbiol. , 2, 1-6.

Chlebicki, A. \& Olejniczak, P. (2007). Symbiotic drift as a consequence of declining host plant populations. Acta Biol. Cracoviensia , 49, 89-93.

Connor, E.F. \& McCoy, E.D. (1979). The statistics and biology of the species-area relationship. Am. Nat. , $113,791-833$.

Cordero, R.J.B., Robert, V., Cardinali, G., Arinze, E.S., Thon, S.M. \& Casadevall, A. (2018). Impact of yeast pigmentation on heat capture and latitudinal distribution. Curr. Biol. , 28, 2657-2664.

Cox, F., Newsham, K.K., Bol, R., Dungait, J.A.J. \& Robinson, C.H. (2016). Not poles apart: Antarctic soil fungal communities show similarities to those of the distant Arctic. Ecol. Lett. , 19, 528-536.

Dadachova, E. \& Casadevall, A. (2008). Ionizing radiation: how fungi cope, adapt, and exploit with the help of melanin. Curr. Opin. Microbiol. , 11, 525-531.

Dale, J., Dunn, P.O., Figuerola, J., Lislevand, T., Székely, T. \& Whittingham, L.A. (2007). Sexual selection explains Rensch's rule of allometry for sexual size dimorphism. Proc. R. Soc. B Biol. Sci. , 274, 2971-2979.

Darcy, J.L., Gendron, E., Sommers, P., Porazinska, D.L. \& Schmidt, S.K. (2018). Island biogeography of cryoconite hole bacteria in Antarctica's Taylor Valley and around the world. Front. Ecol. Evol., 6, 180.

Daufresne, M., Lengfellner, K. \& Sommer, U. (2009). Global warming benefits the small in aquatic ecosystems. Proc. Natl. Acad. Sci. , 106, 12788-12793.

Davison, J., Moora, M., Öpik, M., Ainsaar, L., Ducousso, M., Hiiesalu, I., et al. (2018). Microbial island biogeography: isolation shapes the life history characteristics but not diversity of root-symbiotic fungal communities. ISME J. , 12, 2211-2224.

DeLong, J.P., Okie, J.G., Moses, M.E., Sibly, R.M. \& Brown, J.H. (2010). Shifts in metabolic scaling, production, and efficiency across major evolutionary transitions of life. Proc. Natl. Acad. Sci. , 107, 1294112945.

Dinnage, R., Simonsen, A.K., Barrett, L.G., Cardillo, M., Raisbeck-Brown, N., Thrall, P.H., et al. (2019). Larger plants promote a greater diversity of symbiotic nitrogen-fixing soil bacteria associated with an Australian endemic legume. J. Ecol. , 107, 977-991.

Duarte, S., Barlocher, F., Pascoal, C. \& Cassio, F. (2016). Biogeography of aquatic hyphomycetes: current knowledge and future perspectives. Fungal Ecol. , 19, 169-181.

Dunbar, H.E., Wilson, A.C.C., Ferguson, N.R. \& Moran, N.A. (2007). Aphid thermal tolerance is governed by a point mutation in bacterial symbionts. PLoS Biol , 5, e96.

Duncan, R.P., Forsyth, D.M. \& Hone, J. (2007). Testing the metabolic theory of ecology: allometric scaling exponents in mammals.Ecology , 88, 324-333.

Elias, M., Wieczorek, G., Rosenne, S. \& Tawfik, D.S. (2014). The universality of enzymatic rate-temperature dependency. Trends Biochem. Sci. , 39, 1-7. 
Fernandez, C.W. \& Koide, R.T. (2013). The function of melanin in the ectomycorrhizal fungus Cenococcum geophilum under water stress. Fungal Ecol. , 6, 479-486.

Fierer, N. \& Jackson, R.B. (2006). The diversity and biogeography of soil bacterial communities. Proc. Natl. Acad. Sci. , 103, 626-631.

Foster, J.B. (1964). Evolution of mammals on islands. Nature, 202, 234-235.

Fuhrman, J.A., Steele, J.A., Hewson, I., Schwalbach, M.S., Brown, M. V, Green, J.L., et al. (2008). A latitudinal diversity gradient in planktonic marine bacteria. Proc. Natl. Acad. Sci. , 105, 7774-7778.

Fukami, T., Dickie, I.A., Paula Wilkie, J., Paulus, B.C., Park, D., Roberts, A., et al. (2010). Assembly history dictates ecosystem functioning: evidence from wood decomposer communities. Ecol. Lett. , 13, $675-684$.

Funk, J.L., Cleland, E.E., Suding, K.N. \& Zavaleta, E.S. (2008). Restoration through reassembly: plant traits and invasion resistance. Trends Ecol. Evol. , 23, 695-703.

Gaston, K.J., Blackburn, T.I.M.M., Greenwood, J.D., Gregory, R.D., Quinn, M. \& Lawton, J.H. (2000). Abundance-occupancy relationships.J. Appl. Ecol. , 37, 39-59.

Gaston, K.J., Blackburn, T.M. \& Spicer, J.I. (1998). Rapoport's rule: time for an epitaph? Trends Ecol. Evol. , 13, 70-74.

Gaston, K.J. \& Chown, S.L. (1999). Why Rapoport's rule does not generalise. Oikos , 309-312.

Gillman, L.N., Wright, S.D., Cusens, J., McBride, P.D., Malhi, Y. \& Whittaker, R.J. (2015). Latitude, productivity and species richness. Glob. Ecol. Biogeogr. , 24, 107-117.

Glassman, S.I., Lubetkin, K.C., Chung, J.A. \& Bruns, T.D. (2017a). The theory of island biogeography applies to ectomycorrhizal fungi in subalpine tree "islands" at a fine scale. Ecosphere, 8, e01677.

Glassman, S.I., Wang, I.J. \& Bruns, T.D. (2017b). Environmental filtering by $\mathrm{pH}$ and soil nutrients drives community assembly in fungi at fine spatial scales. Mol. Ecol. , 26, 6960-6973.

Gloger, C.W.L. (1833). Das Abandern der Vogel durch Einfluss des Klima's, etc .

Godon, J.-J., Arulazhagan, P., Steyer, J.-P. \& Hamelin, J. (2016). Vertebrate bacterial gut diversity: size also matters. BMC Ecol. , 16, 12.

Goldford, J.E., Lu, N., Bajić, D., Estrela, S., Tikhonov, M., Sanchez-Gorostiaga, A., et al. (2018). Emergent simplicity in microbial community assembly. Science (80-. ). , 361, 469-474.

Green, H.C., Fisher, J.C., McLellan, S.L., Sogin, M.L. \& Shanks, O.C. (2016). Identification of specialists and abundance-occupancy relationships among intestinal bacteria of Aves, Mammalia, and Actinopterygii. Appl. Environ. Microbiol. , 82, 1496-1503.

Green, J. \& Bohannan, B.J.M. (2006). Spatial scaling of microbial biodiversity. Trends Ecol. Evol. , 21, 501-507.

Green, J., Holmes, A., Westoby, M., Oliver, I., Briscoe, D., Dangerfield, M., et al. (2004). Spatial scaling of microbial eukaryote diversity. Nature, 432, 747-750.

Hanson, C.A., Fuhrman, J.A., Horner-Devine, M.C. \& Martiny, J.B.H. (2012). Beyond biogeographic patterns: processes shaping the microbial landscape. Nat. Rev. Microbiol. , 10, 497-506.

Hawkes, C. V, Waring, B.G., Rocca, J.D. \& Kivlin, S.N. (2017). Historical climate controls soil respiration responses to current soil moisture. Proc. Natl. Acad. Sci. , 114, 6322-6327. 
Hazard, C., Gosling, P., Van Der Gast, C.J., Mitchell, D.T., Doohan, F.M. \& Bending, G.D. (2013). The role of local environment and geographical distance in determining community composition of arbuscular mycorrhizal fungi at the landscape scale. ISME J. , 7, 498-508.

Hedges, L. V \& Olkin, I. (1980). Vote-counting methods in research synthesis. Psychol. Bull. , 88, 359.

Heino, J. \& Soininen, J. (2006). Regional occupancy in unicellular eukaryotes: a reflection of niche breadth, habitat availability or size-related dispersal capacity? Freshw. Biol. , 51, 672-685.

Hendershot, J.N., Read, Q.D., Henning, J.A., Sanders, N.J. \& Classen, A.T. (2017). Consistently inconsistent drivers of microbial diversity and abundance at macroecological scales. Ecology , 98, 1757-1763.

Hillebrand, H. (2004). On the generality of the latitudinal diversity gradient. Am. Nat. , 163, 192-211.

Holt, A.R., Warren, P.H. \& Gaston, K.J. (2002). The importance of biotic interactions in abundanceoccupancy relationships. J. Anim. Ecol. , 846-854.

Holt, A.R., Warren, P.H. \& Gaston, K.J. (2004). The importance of habitat heterogeneity, biotic interactions and dispersal in abundance-occupancy relationships. J. Anim. Ecol. , 841-851.

Honnay, O., Hermy, M. \& Coppin, and P. (1999). Effects of area, age and diversity of forest patches in Belgium on plant species richness, and implications for conservation and reforestation. Biol. Conserv. , 87, 73-84.

Horner-Devine, M.C., Lage, M., Hughes, J.B. \& Bohannan, B.J.M. (2004). A taxa-area relationship for bacteria. Nature, 432, 750-753.

Hubbell, S.P. (2001). The unified neutral theory of biodiversity and biogeography (MPB-32) . Princeton University Press.

Huete-Stauffer, T.M., Arandia-Gorostidi, N., Alonso-Sáez, L. \& Morán, X.A.G. (2016). Experimental warming decreases the average size and nucleic acid content of marine bacterial communities. Front. Microbiol. $, 7,730$.

Hyde, K.D., Fryar, S., Tian, Q., Bahkali, A.H. \& Xu, J. (2016). Lignicolous freshwater fungi along a northsouth latitudinal gradient in the Asian/Australian region; can we predict the impact of global warming on biodiversity and function? Fungal Ecol. , 19, 190-200.

Itescu, Y. (2019). Are island-like systems biologically similar to islands? A review of the evidence. Ecography (Cop.). , 42, 1298-1314.

Jabiol, J., Bruder, A., Gessner, M.O., Makkonen, M., Mckie, B.G., Peeters, E.T.H.M., et al. (2013). Diversity patterns of leaf-associated aquatic hyphomycetes along a broad latitudinal gradient.Fungal Ecol. , $6,439-448$.

Jablonski, D., Roy, K. \& Valentine, J.W. (2006). Out of the tropics: evolutionary dynamics of the latitudinal diversity gradient.Science (80-. ). , 314, 102-106.

Jetz, W. \& Rahbek, C. (2001). Geometric constraints explain much of the species richness pattern in African birds. Proc. Natl. Acad. Sci. , 98, 5661-5666.

Jones, S.E. \& Lennon, J.T. (2010). Dormancy contributes to the maintenance of microbial diversity. Proc. Natl. Acad. Sci. , 107, 5881-5886.

Kettlewell, B. (1973). The evolution of melanism: the study of a recurring necessity . Clarendon Press Oxford.

Kikuchi, Y., Tada, A., Musolin, D.L., Hari, N., Hosokawa, T., Fujisaki, K., et al. (2016). Collapse of insect gut symbiosis under simulated climate change. MBio , 7 . 
Kinkel, L.L., Andrews, J.H., Berbee, F.M. \& Nordheim, E. V. (1987). Leaves as islands for microbes. Oecologia , 71, 405-408.

Kivlin, S.N. (2020). Global mycorrhizal fungal range sizes vary within and among mycorrhizal guilds but are not correlated with dispersal traits. J. Biogeogr.

Kivlin, S.N., Fei, S., Kalisz, S. \& Averill, C. (2020). Microbial Ecology Meets Macroecology: Developing a Process-Based Understanding of the Microbial Role in Global Ecosystems. Bull. Ecol. Soc. Am., 101.

Kivlin, S.N., Winston, G.C., Goulden, M.L. \& Treseder, K.K. (2014). Environmental filtering affects soil fungal community composition more than dispersal limitation at regional scales. Fungal Ecol. , 12, 14-25.

Krah, F.S., Buntgen, U., Schaefer, H., Muller, J., Andrew, C., Boddy, L., et al. (2019). European mushroom assemblages are darker in cold climates. Nat. Commun., 10.

Lear, G., Lau, K., Perchec, A., Buckley, H.L., Case, B.S., Neale, M.,et al. (2017). Following Rapoport's Rule: the geographic range and genome size of bacterial taxa decline at warmer latitudes.Environ. Microbiol. , 19, 3152-3162.

Lennon, J.T. \& Jones, S.E. (2011). Microbial seed banks: the ecological and evolutionary implications of dormancy. Nat. Rev. Microbiol. , 9, 119-130.

Lepere, C., Domaizon, I., Taib, N., Mangot, J.-F., Bronner, G., Boucher, D., et al. (2013). Geographic distance and ecosystem size determine the distribution of smallest protists in lacustrine ecosystems. FEMS Microbiol. Ecol. , 85, 85-94.

Li, S., Wang, P., Chen, Y., Wilson, M.C., Yang, X., Ma, C., et al. (2020). Island biogeography of soil bacteria and fungi: similar patterns, but different mechanisms. ISME J. , 1-11.

Lofgren, L.A., Uehling, J.K., Branco, S., Bruns, T.D., Martin, F. \& Kennedy, P.G. (2019). Genome-based estimates of fungal rDNA copy number variation across phylogenetic scales and ecological lifestyles.Mol. Ecol. , 28, 721-730.

Lokatis, S. \& Jeschke, J.M. (2018). The island rule: an assessment of biases and research trends. J. Biogeogr. , 45, 289-303.

Lomolino, M. V. (1982). Species-area and species-distance relationships of terrestrial mammals in the Thousand Island Region. Oecologia , 54, 72-75.

Loudon, A.H., Venkataraman, A., Van Treuren, W., Woodhams, D.C., Parfrey, L.W., McKenzie, V.J., et al. (2016). Vertebrate hosts as islands: dynamics of selection, immigration, loss, persistence, and potential function of bacteria on salamander skin. Front. Microbiol. , 7, 333.

MacArthur, R.H. \& Wilson, E.O. (1967). The Theory of Island Biogeography. Monogr. Popul. Biol. I. Princet. Univ. Press. Princeton, New Jersey .

Maranon, E. (2015). Cell size as a key determinant of phytoplankton metabolism and community structure.

Marshall, C.T. \& Frank, K.T. (1994). Geographic responses of groundfish to variation in abundance: methods of detection and their interpretation. Can. J. Fish. Aquat. Sci. , 51, 808-816.

Martiny, J.B.H., Bohannan, B.J.M., Brown, J.H., Colwell, R.K., Fuhrman, J.A., Green, J.L., et al. (2006). Microbial biogeography: Putting microorganisms on the map. Nat. Rev. Microbiol. , 4, 102-112.

Martiny, J.B.H., Eisen, J.A., Penn, K., Allison, S.D. \& Horner-Devine, M.C. (2011). Drivers of bacterial $\beta$-diversity depend on spatial scale.Proc. Natl. Acad. Sci. U. S. A. , 108, 7850-7854.

Matheny, P.B., Aime, M.C., Bougher, N.L., Buyck, B., Desjardin, D.E., Horak, E., et al. (2009). Out of the Palaeotropics? Historical biogeography and diversification of the cosmopolitan ectomycorrhizal mushroom family Inocybaceae. J. Biogeogr. , 36, 577-592. 
McCoy, E.D. \& Connor, E.F. (1976). Environmental determinants of island species number in the British Isles. A reconsideration.

Meador, J.A., Baldwin, A.J., Catala, P., Jeffrey, W.H., Joux, F., Moss, J.A., et al. (2009). Sunlight-induced DNA Damage in Marine Micro-organisms Collected Along a Latitudinal Gradient from $70^{\circ} \mathrm{N}$ to $68^{\circ} \mathrm{S}$. Photochem. Photobiol. , 85, 412-420.

Meiri, S. \& Dayan, T. (2003). On the validity of Bergmann's rule.J. Biogeogr. , 30, 331-351.

Milici, M., Tomasch, J., Wos-Oxley, M.L., Wang, H., Jáuregui, R., Camarinha-Silva, A., et al. (2016). Low diversity of planktonic bacteria in the tropical ocean. Sci. Rep. , 6, 1-9.

Mittelbach, G.G. \& Schemske, D.W. (2015). Ecological and evolutionary perspectives on community assembly. Trends Ecol. Evol. , 30, 241-247.

Moeller, A.H., Suzuki, T.A., Lin, D., Lacey, E.A., Wasser, S.K. \& Nachman, M.W. (2017). Dispersal limitation promotes the diversification of the mammalian gut microbiota. Proc. Natl. Acad. Sci., 114, 13768-13773.

Moran, N.A., McCutcheon, J.P. \& Nakabachi, A. (2008). Genomics and evolution of heritable bacterial symbionts. Annu. Rev. Genet. , 42, 165-190.

Narra, H.P. \& Ochman, H. (2006). Of what use is sex to bacteria?Curr. Biol. , 16, R705-R710.

Nemergut, D.R., Schmidt, S.K., Fukami, T., O’Neill, S.P., Bilinski, T.M., Stanish, L.F., et al. (2013). Patterns and processes of microbial community assembly. Microbiol. Mol. Biol. Rev. , 77, 342-356.

Ni, M., Feretzaki, M., Sun, S., Wang, X. \& Heitman, J. (2011). Sex in fungi. Annu. Rev. Genet. , 45, 405-430.

Ogwu, M.C., Takahashi, K., Dong, K., Song, H.-K., Moroenyane, I., Waldman, B., et al. (2019). Fungal elevational Rapoport pattern from a High Mountain in Japan. Sci. Rep. , 9, 1-10.

Okie, J.G., Van Horn, D.J., Storch, D., Barrett, J.E., Gooseff, M.N., Kopsova, L., et al. (2015). Niche and metabolic principles explain patterns of diversity and distribution: theory and a case study with soil bacterial communities. Proc. R. Soc. B Biol. Sci., 282, 20142630.

Passy, S.I. (2010). A distinct latitudinal gradient of diatom diversity is linked to resource supply. Ecology , 91, 36-41.

Peay, K.G., Bruns, T.D., Kennedy, P.G., Bergemann, S.E. \& Garbelotto, M. (2007). A strong species-area relationship for eukaryotic soil microbes: island size matters for ectomycorrhizal fungi. Ecol. Lett. , 10, 470480.

Peay, K.G., Garbelotto, M. \& Bruns, T.D. (2010). Evidence of dispersal limitation in soil microorganisms: isolation reduces species richness on mycorrhizal tree islands. Ecology , 91, 3631-3640.

Peay, K.G., Schubert, M.G., Nguyen, N.H. \& Bruns, T.D. (2012). Measuring ectomycorrhizal fungal dispersal: macroecological patterns driven by microscopic propagules. Mol. Ecol. , 21, 4122-4136.

Price, C.A., Weitz, J.S., Savage, V.M., Stegen, J., Clarke, A., Coomes, D.A., et al. (2012). Testing the metabolic theory of ecology.Ecol. Lett., 15, 1465-1474.

Prosser, J.I., Bohannan, B.J.M., Curtis, T.P., Ellis, R.J., Firestone, M.K., Freckleton, R.P., et al. (2007). The role of ecological theory in microbial ecology. Nat. Rev. Microbiol. , 5, 384-392.

Reche, I., Pulido-Villena, E., Morales-Baquero, R. \& Casamayor, E.O. (2005). Does ecosystem size determine aquatic bacterial richness? Ecology , 86, 1715-1722.

Rensch, B. (1950). Die Abhängigkeit der relativen Sexualdifferenz von der Körpergrösse. Bonner Zool. Beiträge , 1, 58-69. 
Rocha, M.P., Bini, L.M., Siqueira, T., Hjort, J., Grönroos, M., Lindholm, M., et al. (2018). Predicting occupancy and abundance by niche position, niche breadth and body size in stream organisms. Oecologia , $186,205-216$.

Rohde, K. (1978). Latitudinal differences in host-specificity of marine Monogenea and Digenea. Mar. Biol. , 47, 125-134.

Rohde, K. (1996). Rapoport's rule is a local phenomenon and cannot explain latitudinal gradients in species diversity. Biodivers. Lett. , 10-13.

Rohde, K. (1999). Latitudinal gradients in species diversity and Rapoport's rule revisited: a review of recent work and what can parasites teach us about the causes of the gradients? Ecography (Cop.). , 22, 593-613.

Ruggiero, A. \& Werenkraut, V. (2007). One-dimensional analyses of Rapoport's rule reviewed through metaanalysis. Glob. Ecol. Biogeogr., 16, 401-414.

Salerno, J.L., Bowen, B.W. \& Rappe, M.S. (2016). Biogeography of planktonic and coral-associated microorganisms across the Hawaiian Archipelago. FEMS Microbiol. Ecol. , 92, fiw109.

Schardl, C.L., Craven, K.D., Speakman, S., Stromberg, A., Lindstrom, A. \& Yoshida, R. (2008). A novel test for host-symbiont codivergence indicates ancient origin of fungal endophytes in grasses. Syst. Biol. , 57, 483-498.

Schiaffino, M.R., Gasol, J.M., Izaguirre, I. \& Unrein, F. (2013). Picoplankton abundance and cytometric group diversity along a trophic and latitudinal lake gradient. Aquat. Microb. Ecol. , 68, 231-250.

Schiaffino, M.R., Lara, E., Fernandez, L.D., Balague, V., Singer, D., Seppey, C.C.W., et al. (2016). Microbial eukaryote communities exhibit robust biogeographical patterns along a gradient of Patagonian and Antarctic lakes. Environ. Microbiol. , 18, 5249-5264.

Seena, S., Barlocher, F., Sobral, O., Gessner, M.O., Dudgeon, D., McKie, B.G., et al. (2019). Biodiversity of leaf litter fungi in streams along a latitudinal gradient. Sci. Total Environ. , 661, 306-315.

Shade, A., Dunn, R.R., Blowes, S.A., Keil, P., Bohannan, B.J.M., Herrmann, M., et al. (2018). Macroecology to Unite All Life, Large and Small. Trends Ecol. Evol. , 33, 731-744.

Shade, A., Jacques, M.-A. \& Barret, M. (2017). Ecological patterns of seed microbiome diversity, transmission, and assembly. Curr. Opin. Microbiol. , 37, 15-22.

Sinsabaugh, R.L., Shah, J.J.F., Findlay, S.G., Kuehn, K.A. \& Moorhead, D.L. (2015). Scaling microbial biomass, metabolism and resource supply.Biogeochemistry , 122, 175-190.

Soininen, J. (2012). Macroecology of unicellular organisms-patterns and processes. Environ. Microbiol. Rep. , 4, 10-22.

Soininen, J. \& Teittinen, A. (2019). Fifteen important questions in the spatial ecology of diatoms. Freshw. Biol. , 64, 2071-2083.

Sorte, C.J.B., Ibanez, I., Blumenthal, D.M., Molinari, N.A., Miller, L.P., Grosholz, E.D., et al. (2013). Poised to prosper? A cross-system comparison of climate change effects on native and non-native species performance. Ecol. Lett. , 16, 261-270.

Spatharis, S., Dolapsakis, N.P., Economou-Amilli, A., Tsirtsis, G. \& Danielidis, D.B. (2009). Dynamics of potentially harmful microalgae in a confined Mediterranean Gulf-Assessing the risk of bloom formation.Harmful Algae , 8, 736-743.

Spiesman, B.J., Stapper, A.P. \& Inouye, B.D. (2018). Patch size, isolation, and matrix effects on biodiversity and ecosystem functioning in a landscape microcosm. Ecosphere, 9, e02173. 
Stevens, G.C. (1989). The latitudinal gradient in geographical range: how so many species coexist in the tropics. Am. Nat. , 133, 240-256.

Stevens, G.C. (1992). The elevational gradient in altitudinal range: an extension of Rapoport's latitudinal rule to altitude. Am. Nat. , 140, 893-911.

Sul, W.J., Oliver, T.A., Ducklow, H.W., Amaral-Zettler, L.A. \& Sogin, M.L. (2013). Marine bacteria exhibit a bipolar distribution. Proc. Natl. Acad. Sci. , 110, 2342-2347.

Takacs-Vesbach, C., Mitchell, K., Jackson-Weaver, O. \& Reysenbach, A. (2008). Volcanic calderas delineate biogeographic provinces among Yellowstone thermophiles. Environ. Microbiol. , 10, 1681-1689.

Takiya, D.M., Tran, P.L., Dietrich, C.H. \& Moran, N.A. (2006). Co-cladogenesis spanning three phyla: leafhoppers (Insecta: Hemiptera: Cicadellidae) and their dual bacterial symbionts. Mol. Ecol. , 15, 41754191.

Talbot, J.M., Bruns, T.D., Taylor, J.W., Smith, D.P., Branco, S., Glassman, S.I., et al. (2014). Endemism and functional convergence across the North American soil mycobiome. Proc. Natl. Acad. Sci. , 111, 6341-6346.

Tanesaka, E. (2012). Colonizing success of saprotrophic and ectomycorrhizal basidiomycetes on islands. Mycologia , 104, 345-352.

Tedersoo, L., Bahram, M., Polme, S., Koljalg, U., Yorou, N.S., Wijesundera, R., et al. (2014). Global diversity and geography of soil fungi. Science (80-. ). , 346.

Teittinen, A., Kallajoki, L., Meier, S., Stigzelius, T. \& Soininen, J. (2016). The roles of elevation and local environmental factors as drivers of diatom diversity in subarctic streams. Freshw. Biol. , 61, 1509-1521.

Teittinen, A. \& Soininen, J. (2015). Testing the theory of island biogeography for microorganisms patterns for spring diatoms. Aquat. Microb. Ecol. , 75, 239-250.

Van Valen, L. (1973). Body size and numbers of plants and animals.Evolution (N. Y). , 27-35.

Vannette, R.L., Leopold, D.R. \& Fukami, T. (2016). Forest area and connectivity influence root-associated fungal communities in a fragmented landscape. Ecology , 97, 2374-2383.

Vellend, M. (2010). Conceptual synthesis in community ecology. Q. Rev. Biol. , 85, 183-206.

Wang, J. \& Soininen, J. (2017). Thermal barriers constrain microbial elevational range size via climate variability. Environ. Microbiol. , 19, 3283-3296.

Warren, P.H. \& Gaston, K.J. (1997). Interspecific abundance-occupancy relationships: a test of mechanisms using microcosms. J. Anim. Ecol. , 730-742.

Weedall, G.D. \& Hall, N. (2015). Sexual reproduction and genetic exchange in parasitic protists. Parasitology , 142, S120-S127.

West, G.B., Brown, J.H. \& Enquist, B.J. (1997). A general model for the origin of allometric scaling laws in biology. Science (80-. ). , 276, 122-126.

Whitaker, R.J., Grogan, D.W. \& Taylor, J.W. (2003). Geographic barriers isolate endemic populations of hyperthermophilic archaea. Science (80-. ). , 301, 976-978.

Wisnoski, N.I., Muscarella, M.E., Larsen, M.L., Peralta, A.L. \& Lennon, J.T. (2020). Metabolic insight into bacterial community assembly across ecosystem boundaries. Ecology , 101, e02968.

Wu, B., Liu, F., Weiser, M.D., Ning, D., Okie, J.G., Shen, L., et al. (2018). Temperature determines the diversity and structure of N2O-reducing microbial assemblages. Funct. Ecol. , 32, 1867-1878. 
Xu, X., Schimel, J.P., Janssens, I.A., Song, X., Song, C., Yu, G.,et al. (2017). Global pattern and controls of soil microbial metabolic quotient. Ecol. Monogr., 87, 429-441.

Zhou, J., Deng, Y., Shen, L., Wen, C., Yan, Q., Ning, D., et al.(2016). Temperature mediates continentalscale diversity of microbes in forest soils. Nat. Commun., 7. 